\title{
The effectiveness of human resources practices in driving proactive experimentation and risk-taking work behaviours in organisations
}

Authors:
Rose B. Mathafena ${ }^{1}$
Anton Grobler
Affiliations:
'Department Graduate School
for Business Leadership,
Faculty Leadership and
Organisational Behaviour,
University of South Africa,
Midrand, South Africa
Corresponding author:
Rose Mathafena,
rose.mathafena@gmail.com
Dates:
Received: 31 July 2019
Accepted: 06 Oct. 2020
Published: 04 Dec. 2020
mobile device
to read online.
Row to cite this article:
Mathafena, R.B., $\&$ Grobler, A.
(2020). The effectiveness of
human resources practices
in driving proactive
experimentation and
risk-taking work behaviours
in organisations. SA Journal
of Human Resource
Management/SA Tydskrif vir
Menslikehulpbronbestuur,
18(0), a1259. https://doi.
org/10.4102/sajhrm.
v18i0.1259
Copyright:
C 2020. The Authors.
Licensee: AOSIS. This work
is licensed under the
Creative Commons
Attribution License.

Orientation: Proactive experimentation and risk-taking employee behaviours have received considerable attention both empirically and conceptually in organisational learning and development studies, as well as in relation to organisational innovation, entrepreneurship, creativity and continuous improvement capacity.

Purpose: The purpose of the study is to determine the extent to which the perceived human resources practices as well as the person-job fit contribute towards proactive experimentation and risk-taking organisational behaviours.

Motivations for the study: Substantial gaps remain as to how, to what extent and, also, which human resources practices impact on certain organisational outcomes, and more particularly with experimentation and risk-taking.

Research design and methodology: The cross sectional and survey designs were applied in this empirical study. A total of 609 respondents from the diverse South African companies in the private sector participated in the study. Convenience sampling was employed by the field workers in the distribution of the surveys.

Main findings: The regression and correlation analysis indicated a significant relationship between the human resources practices (of training and development, participation in decision-making, rewards) and person-to-job fit with experimentation and risk-taking, whilst recruitment reported somewhat a non-significant and low contribution.

Practical managerial implications: Organisational management will be better enabled to propose concrete human resources strategies necessary for cultivating proactive work behaviours impacting on performance and competitiveness.

Value add: The outcomes of the research corroborate with existing literature according to which rewards, participation in decision-making, training and development, as well as person-job fit are essential for the creation of the conditions which cultivate proactive and productive work behaviours.

Keywords: proactive experimentation; risk-taking; human esources; person-job fit; proactive work behaviour.

\section{Introduction}

\section{Organisational competitive environment}

Organisations operate in increasingly competitive and highly volatile environments (Guinot, Chiva, \& Mallen, 2016); in order to secure the required sustainable growth, development and high performance (Kalmuka \& Acar, 2015), the initiatives contributing towards continuous improvement, organisational learning (Liu, Luo, \& Shi, 2002), adaptation to change, and innovation need attention (Chiva, Alegre, \& Lapiedra 2008). Previous research demonstrates that proactive employee behaviours, such as learning and development (Dermol \& Čater, 2013), continuous improvement (Tohidi \& Jabbari, 2012), development of new and creative ideas (Sutanto, 2017), innovation and entrepreneurship (Arshi \& Burns, 2018; Kalmuka \& Acar, 2015), are driven and underpinned by action-based behaviours such as experimentation and risk-taking (Kreiser \& Davis, 2010; Miron \& Hudson, 2014; Tsai \& Luan, 2016).

Proactive experimentation and risk-taking employee behaviours have received considerable attention both empirically and conceptually in organisational learning and development studies 
(Kreiser \& Davis, 2010; Liu, Luo, \& Shi, 2002; Miron \& Hudson, 2014), as well as in relation to organisational innovation, entrepreneurship (Arshi \& Burns, 2018), creativity and continuous improvement capacity (Sutanto, 2017). The study conducted by Suartha and Suprapti (2016) iterates that proactive employee behaviours enable the identification of opportunities in the market environment leading to product, process and strategy adaptations which are geared towards value-addition business improvement and growth. The propensity of employees to take the initiative has risky and experimental elements to it because of the potential investment of resources in novel and uncertain business (Riabacke, 2006) and also leading to the introduction change. There are several lines of evidence indicating that experimentation and risk-taking behaviours are associated with organisational learning capability and innovation, which improves organisational performance (Kalmuka \& Acar, 2015; Kreiser \& Davis, 2010; Tsai \& Luan, 2016). The aspects of innovation and organisational learning may entail the exploitation and exploration of valuegenerating business opportunities in response to the changing technological, economic, social and market patterns (Farrell, 2000). This study focuses on the proactive and healthy experimentation and risk-taking work behaviour, and not on the dysfunctional, destructive, reckless and irresponsible approach towards risk, which carries predictable negative consequences (Anderson \& Galinsky, 2006).

According to Guinot, Chiva and Mallen (2016), organisations which are capable of identifying, acting and adapting to competitive and dynamic environments through learning, (Chiva, Alegre, \& Lapiedra, 2007) risk-taking and proactivity are better positioned to remain sustainable and competitive (Tsai \& Luan, 2016). Organisations face major challenges of continuously finding ways to cultivate work environments with high capacity for learning (Kalmuka \& Acar, 2015; Sutanto, 2017). Although much research has been performed in areas of innovation, organisational learning, entrepreneurship and creativity (Arshi \& Burns, 2018; Kalmuka \& Acar, 2015; Miron \& Hudson, 2014; Sutanto, 2017; Tohidi \& Jabbari, 2012), which makes several referrals to experimentation and risk-taking behaviours, the contributory role of human resources practices in this regard has not been sufficiently investigated. Various human resource studies have been conducted to assess the impact and value-addition of human resources policies, practices and processes towards the business strategy, overall organisational competitiveness and contribution towards capability development (Delaney \& Huselid, 1996; Kehoe \& Wright, 2013). Nonetheless, there are still knowledge and research gaps about antecedents for experimentation and risk-taking propensity, and how this behaviour can be better encouraged and enhanced in organisations (Tsai \& Luan, 2016). In the recent years, research has reported positive linkages between human resources practices, and also organisational performance (Boon, Den Hartog, Boselie, \& Paauwe, 2011), and the positive behavioural outcomes such as motivation, commitment and mitigated turnover intentions (Kehoe \& Wright, 2013). Substantial gaps remain as to how, to what extent and, also, which human resources practices impact on certain organisational outcomes, and more particularly with experimentation and risk-taking.

This study in particular intends to examine whether the human resources interventions, operationalised as training and development, participation in decision-making, rewards, and recruitment and selection (Edvardsson, 2008; Leat \& ElKot, 2007), translate into improved experimentation as well as risk-taking employee behaviours. In doing so, the human capital practices are examined to determine whether they are a contributor and a mechanism which positively impact on the desirable performance behaviours. Additionally, these practices are examined to explore the extent to which personjob fit impacts on the improvement of experimentation and risk-taking employee behaviours. These concepts are important to study as Wiklund and Shepherd (2011) argue that entrepreneurial orientation characterised by attributes of innovation, risk-taking and proactiveness is consistently linked to the outputs such as active experimentation, new product developments and adaptations of market routes and products. Experimentation and risk-taking work activities are required for the successful development and implementation of new and creative ideas (Spicer \& SadlerSmith, 2006), the finding of productive ways of solving business problems and also improving business capability for continuous adaptations to dynamic and changing markets (Onağ, Tepeci, \& Başalp, 2014).

\section{Research purpose and objectives}

The study hypothesises that proactive experimentation and risk-taking employee behaviours in organisations could be improved and influenced by human resource aspects of training and development, participation in decision-making, rewards, and recruitment and selection, as well as person-job fit. It aims to determine if person-job fit has an effect on experimentation and risk-taking employee behaviour. Lastly, the study seeks to explore the mediating effect of personjob fit on the relationship between the human resources practices - of training and development, participation in decision-making, rewards, and recruitment and selection and experimentation and risk-taking employee behaviours. The objectives of the study are as follows:

1. Determine the relationship between experimentation and (1) training and development, (2) participation in decision-making, (3) rewards, and (4) recruitment and selection.

2. Determine the relationship between risk-taking and (1) training and development, (2) participation in decisionmaking, (3) rewards and (4) recruitment and selection.

3. Determine the relationship between person-job fit, experimentation and risk-taking.

4. Test the mediating effects of person-job fit on the relationship between experimenting employee behaviours and (1) training and development, (2) participation in decision-making, (3) rewards and (4) recruitment and selection. 
5. Test the mediating effects of person-job fit on the relationship between risk-taking employee behaviours and (1) training and development, (2) participation in decision-making, (3) rewards and (4) recruitment and selection.

\section{Literature review: Theoretical concepts underpinning the study Experimentation and risk-taking employee work behaviour}

Chiva et al. (2008) suggest that employee experimentation and risk-taking behaviours are bi-dimensional concepts and an integral element of organisational learning capacity, together with team dialogue, external networking and participation in decision-making.

\section{Experimenting employee behaviours}

Experimenting employee behaviours refers to the measure of freedom an employee has to exploit and pursue new and improved ways of performing their tasks (Terziovski, 2001). On the other hand, experimentation from an organisational and managerial perspective refers to the extent to which their ideas and suggestions are attended to, and the manner in which they are dealt with (Onağ, Tepeci, \& Başalp, 2014). Experimentation from an organisational learning perspective can be either through exploration or through exploitation (Wiklund \& Shepherd, 2011). Exploitation entails capitalisation on the existing competencies and practices, through continuous improvement, refining, re-modelling of existing products or services and the adaptation of processes (Kane \& Alavi, 2007). Exploration, on the other hand, is about venturing into new ideas and introducing products, services and processes which are new and unknown to the organisation (Kane \& Alavi, 2007). Essentially exploration generates internal variance between knowledge possessed and the learning required, which is outside of the organisation's existing capabilities, knowledge base and skills and provides opportunities for learning and a potential for innovativeness. Learning organisations allow for new ideas and suggestions to be accommodated through trials, making adjustments to work processes, critical questioning of existing practices and searching for new and improved work methodologies (Chiva et al., 2008).

\section{Risk-taking behaviours}

Risk-taking behaviours allude to tolerance for risk, uncertainty, ambiguity and errors from the employee, managerial and organisational perspectives (Chiva et al., 2008). Risk-taking inclinations come with and carry the assumption that making mistakes and occurrence of failure is part of organisational learning (Cannon \& Edmondson, 2005). Exploration of new and novel ideas brings with it some level of risk and uncertainty because of variability in skills, resources and competence requirements for implementing new ventures (Wiklund \& Shepherd, 2011). As per Chiva et al. (2008), organisational change and learning is facilitated through tolerance for risk-taking and acceptance of mistakes as a learning platform, and also the view that learning can be derived from reflecting on the success and failure arising from risk-taking initiatives of which the insights can unearth business opportunities. Furthermore, risk-taking entails the willingness to take up business opportunities that may be profitable or bring about losses (Tsai \& Luan, 2016). According to Wiklund and Shepherd (2011), proactive and learning organisational cultures do not necessarily hold a paralysing view of failure; however, failure is seen as an ordinary occurrence, providing opportunities for learning and a potential for innovativeness. Urban (2015) states that risk-taking behaviours include employee involvement in projects such as innovations, new product and process development, as well as pursuing new opportunities, including new technologies and new market possibilities with the aim of creating value.

\section{Human resources practice}

Empirical findings of Bhatti and Qureshi (2007), Kehoe and Wright (2013) and Sung and Choi (2014) support the positive and significant relationships between human capital practices and organisational performance outcomes. The literature analysis of Boon et al. (2011) iterates that human capital elements are able to motivate as well as create enabling systems and mechanisms which promote proactive and improved performance-related behaviours. As per Mathews (2006), human resources activities are intended to enhance positive contribution towards the creation, improvement and maintenance of organisational competitiveness through the acquisition, development and retention of high-quality human capital skills in the organisation. Han, Chiang and Chang (2010) view human capital as a strategic asset of the organisation in which tacit and intangible knowledge is contained and embedded. Human resources systems on the other hand are meant to discover and unleash the human capital outputs through motivation, engagement, commitment and learning in order to achieve organisational performance.

\section{Participation in decision-making in relation to experimentation and risk-taking}

Kuratko, Hornsby and Covin (2014) assert that employees with decision-making latitude and freedom from excessive oversight concerning their work are likely to participate in risk and experimentation activities which are creative, innovative and entrepreneurial in nature. Han et al. (2010) support the premise that employees who participate in decision-making are closely attached to organisational strategic objectives. Additionally, participation in decisionmaking creates a sense of ownership, commitment and responsible self and job management in the work context. The spirit of democracy and altruism experienced through participation in decision-making also leads to feelings of psychological ownership and creates a sense of belonging. Furthermore, human needs for growth, development and self-actualisation are realised, which in turn cultivates high performance, continuous improvement and increased commitment. Irawanto (2015) found participation to be 
critical for employee work motivation, as it is a mental and emotional process reflective of employee contribution towards organisational success, which has long-term loyalty and commitment implications.

Bhatti and Qureshi's (2007) study reported a strong relationship between employee participation in decisionmaking and job satisfaction, employee commitment and productivity. Han et al. (2010) argue that the involvement of employees ignites their commitment and psychological ownership, which translates into positive attitudes and behaviours. Furthermore, involvement appeals to the humanistic needs for achievement, inclusion and having a sense of contribution. Kuyea and Sulaimonb (2011) emphasise the significant need for enterprises to involve employees in decision-making processes as a possible means to improve performance during and in uncertain times characterised by highly competitive market variables. Their findings also suggested that firms that involve employees in decisionmaking outperform their competitors. The literature presentation suggests that employee participation in key organisational decisions, positively enhances employee behaviours and attitudes which are critical for performance improvement. Considering these arguments pertaining to the relationship between proactive organisational behaviours and participation in decision-making, the study proposes to determine the relationship between participation in decisionmaking and experimentation and risk-taking.

\section{Training and development in relation to experimentation and risk-taking}

Sung and Choi (2014) associate the investment in learning and development with the development of the competitive human capital pool within an organisation. Exposure to broad perspectives, new insights, knowledge and skills creates opportunities for new idea generation, creativity and constructive inputs towards performance improvements. Although training and development is a contributor towards innovation, generated knowledge and ideas still need to be translated into actionable activities requiring experimentation and risk-taking. Development interventions delivered through human resources provide skills and competence required to adapt and cope with change, as well as for the development of creativity, innovation, problem solving and proactive work behaviours (Mathews, 2006). According Dermol and Čater (2013), training leads to learning, development and growth of employees, which positively improves performance, productivity and adaptation to market developments. In other words, impactful training drives behaviours, which in turn generates business results. Niazi (2011) strongly recommends training and development interventions which are aligned to organisational performance and strategic requirements in order to impact on competitiveness. According to Falola, Osibanjo and Ojo (2014), training and development is critical in enabling adaptive abilities of employees to the changing business and technological environment for better performance and increased knowledge needed for creativity and problem solving. In the context of proactive and performance-enhancing interventions, training and development which characterises skills, knowledge and competence acquisition may stimulate creativity, innovation and continuous improvement at a task, process, service and product level, and if actioned, could result in work activities requiring experimentation and risk-taking work behaviours. Therefore, the study proposes to examine the relationship between training and development and experimentation and risk-taking.

\section{Recruitment and selection in relation to experimentation and risk-taking}

Organisations need to adopt proactive human resources practices of recruitment and selection by employing people with required attributes, which will directly contribute towards challenging of conventions, problem solving, knowledge generation and exploratory learning. Steiber and Alänge (2013) found that innovativeness of the organisation is reflective of their human capital commitment, skills diversity and depth in competence, for which recruitment matters. Employment processes are critical for filtering in the recruits who have cognitive abilities, values and the required role-knowledge fit. Martins and Terblanche (2003) argue that innovative, creative and risk-taking organisational cultures are supported by the recruitment, selection and appointment of employees with the required traits with regard to knowledge, inquisitiveness, risk-taking, diversity and creativity. Ahmad and Schroeder (2002) are of the view that an organisation with the right training, systems, processes, communication strategy, teamwork and empowerment in improving quality management systems has the right enablers in place; however, without the recruitment of the right people all these efforts are undermined and become less impactful. Hsiao, Chang, Huang and Chen (2011) strongly argue for a rigorous recruitment and selection process to improve the quality of recruitment decision, as it impacts on the organisational capacity and capability. Recruitment and selections ensure the attraction and acquisition of highquality talent with the matching knowledge, skills, attitudes, experience and values which are specific to the job and organisation's requirements. The selection methods and processes must have the required reliability to improve the quality and accuracy of recruitment decisions, supportive of organisational performance and the strategic goals (Fong, Ooi, Tan, Lee, \& Chong, 2011). Taking the arguments from the previously discussed literature into account, the study proposes to examine the relationship between recruitment and selection and experimentation and risk-taking.

\section{Rewards in relation to experimentation and risk-taking}

Research on corporate entrepreneurship has identified organisational reward systems as one of the dimensions which support and encourage risk-taking and innovation, which drives entrepreneurial tendencies amongst employees (Kuratko et al., 2014). The rewarding of employees for learning, generating and experimenting with new ideas for improvements, is as important as rewarding them for tangible productive outputs (Nafukho, Graham, \& Muyia, 
2009). The literature analysis conducted by Jerez-Gómez, Céspedes-Lorente and Valle-Cabrera (2005) proposes that compensation systems should be designed to drive individual and team behaviours towards organisational strategic outputs. Desired behaviours should be rewarded so that they become dominant and part of the organisational culture. Furthermore, skills-based pay is associated with learning orientation and experimentation. Jerez-Gómez et al. (2005) advocate for high pay incentives for employees who are willing to experiment, innovate and search for new ideas before they are even tested, and it is important to note that this suggestion carries with it an element of risk and the possibility of failure. Outcome-based pay reduces activities with a high element of uncertainty and risk. Whilst on the other hand, long-term incentives are suited for rewarding those who are willing to learn, continuously improve and introduce creative and new ideas whose results could be realised in a longer term. Alpkan, Bulut, Gunday, Ulusoy and Kilic (2010) assert that organisations requiring entrepreneurial and risk-taking behaviour must be able to reward people as inventors and entrepreneurs, and the organisational environment must provide support for risky outcomes by avoiding harsh punishment for the failure associated with experimentation and risk-taking. Hsieh and Chen (2011), being motivated by the strategic approach to implementing rewards, argue that rewards must be designed to attract, retain and motivate employees, as employees contribute towards strategic objectives and competitive advantage of the organisation. Kwon, Hewitt and Hein's (2013) total reward study found that high-performing companies align their rewards to the business strategy, and clearly illustrate the link between the total rewards to business, and the business to employees' performance and behaviours. Drawing from the motivation theories, both compensation and rewards have potential to re-enforce proactive and positive performance-related behaviours, which are rewarded and recognised by the organisation (Fong et al., 2011). The study proposes that rewards positively contribute towards the improvement of experimentation and risktaking employee behaviours.

\section{Person-job fit in relation to experimentation and risk-taking}

According to Lu, Wang, Lu, Du and Bakker (2014), as well as Kristof-Brown (2000), person-job fit refers to the match and congruence between a person's characteristics and also job characteristics. Primarily, the perceived fit occurs when a person's skills, abilities, knowledge, experience and competence match with that of the job requirements and demands. The essence of this theory proposes that the more the person's characteristics are aligned to the job, the more likely they are to meet performance and task requirements. Iplik, Kilic and Yalcin (2011) assert that fit is associated with positive outcomes such as commitment, motivation, job satisfaction and also job-related stress. The consequences of poor job fit are poor performance, human resources problems, turnover and absenteeism. Li and Hung's (2010) empirical findings suggested that person-job fit is correlated to job performance, as well as organisational citizenship behaviours.
Furthermore, technical knowledge and information literacy related to the job improves person-job fit considerably. The study conducted by June and Mahmood (2011) reported a significant relationship between person-job fit, competency and performance, and further recommends that role ambiguity be overcome through adequate information sharing and communication pertaining to the role. Based on the aforementioned literature review on person-job fit, employee performance and behavioural outcomes, the study proposes to establish the link between person-job fit with both experimentation and risk-taking employee behaviours.

\section{Indirect effect: The mediating role of person-job fit}

Boon et al. (2011) assert that person-job fit is about the match between the individual's skills, abilities, competencies, experience and knowledge in relation to the job tasks and responsibilities. Importantly, human resources practices, such as recruitment, learning and development, are critical in facilitating person-job fit, with the rewards to encourage motivation towards performance and participation in critical organisational projects. Hartog et al.'s (2011) study found a significant relationship between human resources practices and person-job fit. Additionally, person-job fit was found to have mediating effects on relationship between human resource practices and performance outcomes, work attitudes and behaviours. Li and Hung (2010) recognise the role of person-job fit as a predictor of work performance as well as having mediating effects related to work outcomes.

Table 1 summarises the research hypothesis, which will enable the study to address the research objectives through the relevant statistical procedures.

\section{Research methods}

\section{Settings, study population and sampling strategy}

In order to investigate the relationships between the operationalised human capital practices, person-job fit and also organisational learning capability elements of experimentation and risk-taking, an empirical study was conducted from employees of various private and public sector organisations in South Africa. The diverse industries represented consisted of tourism, consulting, energy, banking, information technology, health, manufacturing, agriculture and also chemical. Convenience sampling was employed, as it was deemed appropriate in the context to yield adequate response levels (Leedy \& Ormrod, 2016). The final sample consisted of a total 609 responses which were received after manually clearing the missing data of less than $1.4 \%$. In total $30.2 \%$ were management, whilst $69.8 \%$ were non-management. The average tenure of employees is 7 years. A total of $40.4 \%$ were in core positions, and the remainder in support. The average age of the participants is 36 years. Participants in the core positions account for a total of $49 \%$. 
TABLE 1: Summary of the research hypothesis.

\begin{tabular}{|c|c|}
\hline Hypothesis & Description \\
\hline $\mathrm{H} 1 \mathrm{a}$ & $\begin{array}{l}\text { There is a positive relationship between training and development } \\
\text { and experimentation }\end{array}$ \\
\hline $\mathrm{H} 1 \mathrm{~b}$ & $\begin{array}{l}\text { There is a positive relationship between participation in decision- } \\
\text { making and experimentation }\end{array}$ \\
\hline $\mathrm{H} 1 \mathrm{C}$ & There is a positive relationship between rewards and experimentation \\
\hline $\mathrm{H} 1 \mathrm{~d}$ & $\begin{array}{l}\text { There is a positive relationship between recruitment and selection } \\
\text { and experimentation }\end{array}$ \\
\hline $\mathrm{H} 2 \mathrm{a}$ & $\begin{array}{l}\text { There is a positive relationship between training and development } \\
\text { and risk-taking }\end{array}$ \\
\hline $\mathrm{H} 2 \mathrm{~b}$ & $\begin{array}{l}\text { There is a positive relationship between participation in decision- } \\
\text { making and risk-taking }\end{array}$ \\
\hline $\mathrm{H} 2 \mathrm{C}$ & There is a positive relationship between rewards and risk-taking \\
\hline $\mathrm{H} 2 \mathrm{~d}$ & $\begin{array}{l}\text { There is a positive relationship between recruitment and selection } \\
\text { and risk-taking }\end{array}$ \\
\hline $\mathrm{H} 3 \mathrm{a}$ & $\begin{array}{l}\text { There is a positive relationship between person-job fit and } \\
\text { experimentation }\end{array}$ \\
\hline $\mathrm{H} 3 \mathrm{~b}$ & There is a positive relationship between person-job fit and risk-taking \\
\hline $\mathrm{H} 4 \mathrm{a}$ & $\begin{array}{l}\text { Person-job fit mediates the relationship between training and } \\
\text { development and experimentation }\end{array}$ \\
\hline $\mathrm{H} 4 \mathrm{~b}$ & $\begin{array}{l}\text { Person-job fit mediates the relationship between participation in } \\
\text { decision-making and experimentation }\end{array}$ \\
\hline $\mathrm{H} 4 \mathrm{c}$ & $\begin{array}{l}\text { Person-job fit mediates the relationship between rewards and } \\
\text { experimentation }\end{array}$ \\
\hline $\mathrm{H} 4 \mathrm{~d}$ & $\begin{array}{l}\text { Person-job fit mediates the relationship between recruitment and } \\
\text { selection and experimentation }\end{array}$ \\
\hline $\mathrm{H} 5 \mathrm{a}$ & $\begin{array}{l}\text { Person-job fit mediates the relationship between training and } \\
\text { development and risk-taking }\end{array}$ \\
\hline $\mathrm{H} 5 \mathrm{~b}$ & $\begin{array}{l}\text { Person-job fit mediates the relationship between participation in } \\
\text { decision-making and risk-taking }\end{array}$ \\
\hline $\mathrm{H} 5 \mathrm{C}$ & $\begin{array}{l}\text { Person-job fit mediates the relationship between rewards and } \\
\text { risk-taking }\end{array}$ \\
\hline $\mathrm{H} 5 \mathrm{~d}$ & $\begin{array}{l}\text { Person-job fit mediates the relationship between recruitment and } \\
\text { selection and risk-taking }\end{array}$ \\
\hline
\end{tabular}

\section{Research approach and design}

The study takes the ontological position of objectivism, with a positivistic epistemology. According to Botma, Greeff, Mulaudzi and Wright (2010), epistemology determines the methodologies, theories and procedure application throughout the research process. Therefore, a quantitative and non-experimental research approach was adopted. Leedy and Ormrod (2016) highlight that descriptive quantitative research entails the identification and exploration of characteristics of the phenomenon and possible correlations amongst the multiple phenomena. A self-administered questionnaire survey design was utilised for data collection purposes.

The questionnaires which are in English were distributed by the master's students who are part of a team-based research programme. The students were required to obtain 60 responses from their organisations; furthermore, the returned responses with missing values were excluded from the analysis.

\section{Measuring instruments}

The instruments utilised for the data collection purposes are the perceived human resources practices, person-to-job fit and also the organisational learning capacity instrument with a specific focus on the variables of experimentation and risk-taking.

\section{Perceived human resources practices}

The scale developed by Boon et al. (2011) measures the employees' perceptions of human resources practices in their respective organisation. Most human resources high performance and best practice systems are incorporated in the instruments such as autonomy, recruitment and selection, rewards, job security, work-life balance, teamwork and autonomy. The reported Cronbach's alpha in the recent South Africa study for human resources operationalised sub-scales are 0.82 for training, 0.85 for participation, 0.87 for rewards and 0.87 for recruitment and selection (Grobler, Grobler, \& Mathafena, 2019), which is indicative of high internal reliability in accordance with Pallant (2016). The sub-scales consist of a total of 23 items and are on a fivepoint Likert scale where the participants were to indicate the extent of their disagreement or agreement from strongly disagree (1) to strongly agree (5). The first items read as follows: Training and development The opportunity to follow training, courses and workshops; Participation The opportunity to participate in decision-making processes; Rewards Performancerelated pay; and Recruitment and Selection Critical selection of new employees.

\section{Person-to-job fit}

The scale developed by Cable and De Rue (2002) intends to measure the extent to which the participants perceive themselves to be fitting to the organisation's values and culture and also whether their skills match to the job demands.

The scale pertaining to job demands and skills fit tested to have high reliability with a Cronbach's alpha coefficient of 0.84 for a multiple company study, and 0.89 for a single company study (Cable \& De Rue, 2002), whilst Grobler's (2016) multiple empirical studies reported mean Cronbach's alpha coefficient of 0.89 . One of the six items of the scale reads as follows: The match is very good between the demands of my job and my personal skills. The scale for person-to-job fit was administered with a five-point Likert scale, ranging from strongly disagree (1) to strongly agree (5).

\section{Experimentation and risk-taking behaviours}

Organisational learning capacity instrument, which was developed and validated by Chiva, Alegre and Lapiedra (2007), was used to derive the sub-scales of experimentation and risk-taking behaviours. The confirmatory factor analysis reported the composite reliabilities for experimentation as 0.78 and risk-taking as 0.65 , and the Cronbach's alphas of 0.89 and 0.74 respectively. The instruments consist of a seven-point Likert scale, ranging from strongly disagree (1) to strongly agree (7). The first items for each sub-scale read as follows: Experimentation People here receive support and encouragement when presenting new ideas and Risk-Taking 'People are encouraged to take risks in this organisation'.

\section{Data analysis}

The statistical analysis was conducted using the Statistical Package for the Social Sciences (SPSS) version 25 and also the PROCESS Procedure for SPSS version 3.1. 
The analysis included the descriptive statistics (means, standard deviation), and the internal consistency of the instruments was determined by the Cronbach's alpha coefficients (with 0.70 as guideline) (Pallant, 2016). Correlations and multiple regression analysis were conducted through Pearson product moment. Mediation analysis was conducted to test the indirect effect of person-job fit on both experimentation and risk-taking employee behaviours (dependent variables), as well as the independent variables of training and development, participation in decisionmaking, rewards and also recruitment.

\section{Results}

Table 2 indicates the output of the descriptive statistics. The true mean value in the population falls within the stipulated ranges, at 95\% confidence interval levels (Pallant, 2016). Furthermore, the original mean scores were compared with the $5 \%$ trimmed mean, the differences across the variables were low and ranging from $0.01,0.02$ to 0.03 . This indicated that the extreme scores do not influence the mean. Kolmogorov-Smirnov and Shapiro-Wilk statistics was utilised to assess the normality of the distribution of the scores (Pallant, 2016), which reported 0.000 statistical significance in that the values are less than 0.05 which violates the assumption of normality of distribution. Nonetheless, this is common with larger samples according to (Pallant, 2016). Furthermore, a visual inspection of the histograms and the normal Q-Q plot was conducted in the background. Both the histograms and the normal Q-Q plot were reasonably normal. Griffin and Steinbrecher (2013) recommend acceptable values for skewness as being $(-3$ to +3$)$ and kurtosis $(-10$ to +10$)$, the descriptive report provided are within the recommended ranges of Griffin and Steinbrecher (2013). The internal consistency of the human resources, person-job fit and also experimentation and risk-taking scales were reported to be good with the Cronbach's alpha reliability coefficients being between 0.76 and 0.92 .

The Pearson product-moment correlation coefficient according to Pallant (2016), assisted in the analysis of the strength of the relationship between experimentation and training and development, participation in decisionmaking, rewards, recruitment and selection as well as person-to-job fit (Table 3). Similarly, the same determination was conducted for risk-taking. With regards to experimentation behaviour, high correlation was identified in terms of rewards $(r=0.50 ; p<0.01)$, with medium correlation for participation in decision-making $(r=0.49$; $p<0.01)$, training and development $(r=0.46 ; p<0.01)$ and person-job fit $(r=0.44 ; p<0.01)$, and a low correlation for recruitment and selection $(r=0.12 ; p<0.01)$.

The strength of the relationships between risk-taking behaviour and other variables indicated medium strength for rewards $(r=0.37 ; p<0.001)$, participation in decision-making $(r=0.36 ; p<0.001)$, training and development $(r=0.34 ; p<$ $0.001)$ and person-job fit $(r=0.32 ; p<0.001)$, and low relationship for recruitment and selection $(r=0.15 ; p<0.001)$. Furthermore, the correlations between the independent variables were not too high, and are below 0.62 , in order to avoid the inclusion of two variables with bivariate correlation of 0.70 and more.

The model summary (Table 4$) R$ square value indicates a total variance of $34 \%$ in experimenting employee behaviours when all the independent variables are entered into the model, whilst the total variance of $18 \%$ is explained by the influence of the collective independent variables on risktaking behaviours. Both the contributions are statistically significant at $p<0.001$ for both experimentation and risktaking.

Multicollinearity tested negatively (Table 5), with all the tolerance values for both experimentation and risk-taking behaviour being higher than 0.10 . Furthermore, the variance inflation factor (VIF) reported less than 10 based on Pallant (2016). The results for experimentation indicate statistically significant unique contribution by rewards $(\beta=0.23, p<$ $0.001)$, participation in decision-making $(\beta=0.20, p<0.001)$,

TABLE 3: Correlation analysis $(n=609)$.

\begin{tabular}{|c|c|c|c|c|c|c|c|}
\hline Variables & OL_Exp & OL_Risk & HR_TD & HR_PAJ & HR_PAR & HR_RS & PoF_JF \\
\hline OL_Exp & 1.00 & & & & & & \\
\hline OL_Risk & 0.58 & 1.00 & & & & & \\
\hline HR_TD & 0.46 & 0.34 & 1.00 & & & & \\
\hline HR_PAJ & 0.49 & 0.36 & 0.62 & 1.00 & & & \\
\hline HR_PAR & 0.50 & 0.37 & 0.58 & 0.61 & 1.00 & & \\
\hline HR_RS & 0.12 & 0.15 & 0.32 & 0.35 & 0.23 & 1.00 & \\
\hline PoF_JF & 0.44 & 0.32 & 0.47 & 0.52 & 0.49 & 0.15 & 1.00 \\
\hline
\end{tabular}

HR TD, Training; HR PAJ, Participation in decision; HR PAR, Rewards; HR RS, Recruitment; PoF_JF, Person-job fit; OL_Exp, Experimentation; OL_Risk, Risk taking; PoF_JF, Person-job fit. All $\bar{p}<0.001$ (2-tailed).

TABLE 2: Descriptive statistics.

\begin{tabular}{|c|c|c|c|c|c|c|c|c|}
\hline A2-sector & Cronbach's alpha & Range & Min & Max & Mean & SD & Skewness & Kurtosis \\
\hline \multicolumn{9}{|l|}{ Private } \\
\hline HR_TD & 0.87 & 3.78 & 1.00 & 4.78 & 3.19 & 0.72 & -0.39 & 0.07 \\
\hline HR_PAJ & 0.89 & 3.78 & 1.22 & 5.00 & 3.32 & 0.80 & -0.24 & -0.73 \\
\hline \multicolumn{9}{|c|}{ Valid $N$ (listwise) 609} \\
\hline HR_PAR & 0.87 & 3.88 & 1.13 & 5.00 & 3.11 & 0.73 & -0.28 & -0.21 \\
\hline HR_RS & 0.86 & 4.00 & 1.00 & 5.00 & 2.62 & 1.07 & 0.15 & -0.84 \\
\hline PoF_JF & 0.86 & 4.00 & 1.00 & 5.00 & 3.38 & 0.77 & -0.59 & 0.17 \\
\hline OL_Exp & 0.92 & 6.00 & 1.00 & 7.00 & 4.32 & 1.58 & -0.28 & -0.68 \\
\hline OL_Risk & 0.76 & 6.00 & 1.00 & 7.00 & 3.57 & 1.46 & 0.05 & -0.60 \\
\hline
\end{tabular}

SD, standard deviation; HR_TD, Training; HR_PAJ, Participation in decision; HR_PAR, Rewards; HR_RS, Recruitment; OL_Exp, Experimentation; OL_Risk, Risk-taking; PoF_JF, Person-job fit. 
TABLE 4: Regression analysis.

\begin{tabular}{|c|c|c|c|c|c|c|c|c|c|c|}
\hline \multirow[t]{2}{*}{ Model summary } & & \multirow[t]{2}{*}{$\boldsymbol{R}$} & \multirow[t]{2}{*}{$R$ square } & \multirow{2}{*}{$\begin{array}{l}\text { Adjusted } R \\
\text { square }\end{array}$} & \multirow{2}{*}{$\begin{array}{l}\text { Std. error of } \\
\text { the estimate }\end{array}$} & \multicolumn{4}{|c|}{ Change statistics } & \multirow[b]{2}{*}{ Sig. $F$ change } \\
\hline & & & & & & $\begin{array}{l}R \text { square } \\
\text { change }\end{array}$ & $F$ change & df1 & df2 & \\
\hline \multicolumn{11}{|c|}{ Experimentation behaviours } \\
\hline Private & 1 & $0.58 \dagger$ & 0.34 & 0.33 & 1.30 & 0.34 & 61.74 & 5 & 603 & $p<0.001$ \\
\hline \multicolumn{11}{|l|}{ Risk behaviours } \\
\hline Private & 1 & $0.43 \dagger$ & 0.18 & 0.18 & 1.33 & 0.18 & 26.75 & 5 & 603 & $p<0.001$ \\
\hline
\end{tabular}

$\dagger$, Predictors: (Constant), PoF_JF, HR_RS, HR_PAR, HR_TD, HR_PAJ.

\$, Dependent variable: OL_Exp, OL_Risk.

HR_TD, Training; HR_PAJ, Participation in decision; HR_PAR, Rewards; HR_RS, Recruitment; OL_Exp, Experimentation; OL_Risk, Risk-taking; PoF_JF, Person-job fit.

TABLE 5: Unique contribution indicated by the coefficients.

\begin{tabular}{|c|c|c|c|c|c|c|c|c|c|}
\hline \multirow[t]{2}{*}{ Variables } & \multicolumn{2}{|c|}{ Unstandardised coefficients } & \multirow{2}{*}{$\frac{\text { Standardised coefficients }}{\text { Beta }}$} & \multirow[t]{2}{*}{$T$} & \multirow[t]{2}{*}{ Sig. } & \multicolumn{2}{|c|}{$95 \% \mathrm{Cl}$ for $\mathrm{B}$} & \multicolumn{2}{|c|}{ Collinearity statistics } \\
\hline & B & Std. error & & & & Lower bound & Upper bound & Tolerance & VIF \\
\hline \multicolumn{10}{|c|}{ Experimentation behaviours } \\
\hline Constant & -0.38 & 0.29 & - & -1.30 & 0.193 & -0.94 & 0.19 & - & - \\
\hline HR_TD & 0.32 & 0.100 & 0.15 & 3.19 & 0.001 & 0.12 & 0.52 & 0.53 & 1.90 \\
\hline HR_PAJ & 0.39 & 0.10 & 0.20 & 4.11 & 0.000 & 0.21 & 0.58 & 0.47 & 2.14 \\
\hline HR_PAR & 0.50 & 0.10 & 0.23 & 5.07 & 0.000 & 0.30 & 0.69 & 0.54 & 1.86 \\
\hline HR_RS & -0.11 & 0.05 & -0.07 & -2.02 & 0.043 & -0.21 & -0.013 & 0.86 & 1.17 \\
\hline PoF_JF & 0.33 & 0.08 & 0.16 & 3.93 & 0.000 & 0.16 & 0.49 & 0.66 & 1.51 \\
\hline \multicolumn{10}{|c|}{ Risk-taking behaviours } \\
\hline Constant & 0.29 & 0.30 & - & 0.99 & 0.322 & -0.29 & 0.87 & - & - \\
\hline HR_TD & 0.19 & 0.10 & 0.10 & 1.90 & 0.058 & -0.01 & 0.40 & 0.53 & 1.90 \\
\hline HR_PAJ & 0.21 & 0.108 & 0.11 & 2.12 & 0.034 & 0.02 & 0.40 & 0.47 & 2.14 \\
\hline HR_PAR & 0.34 & 0.10 & 0.17 & 3.41 & 0.001 & 0.14 & 0.54 & 0.54 & 1.86 \\
\hline HR_RS & 0.03 & 0.05 & 0.02 & 0.59 & 0.559 & -0.08 & 0.14 & 0.86 & 1.17 \\
\hline
\end{tabular}

HR_TD, Training; HR_PAJ, Participation in decision; HR_PAR, Rewards; HR_RS, Recruitment; OL_Exp, Experimentation; OL_Risk, Risk-taking; PoF_JF, Person-job fit; VIF, variance inflation factor.

person-job fit $(\beta=0.16, p<0.001)$ and training and development $(\beta=0.15, p<0.001)$, and non-significant and low contribution by recruitment and selection $(\beta=-0.07, p<$ $0.001)$. The unique contribution for risk-taking behaviour indicated rewards $(\beta=0.17, p<0.001)$, person-job fit $(\beta=0.13$, $p<0.001)$, participation in decision-making $(\beta=0.11, p<$ $0.001)$, whilst training and development $(\beta=0.09, p<0.001)$ and recruitment and selection $(\beta=0.02, p<0.001)$ made a non-significant and low contribution.

Mediation analysis was conducted through PROCESS model 4 , which is based on the simple principles of linearity applicable to regression analysis (Field, 2018; Hayes \& Preacher, 2014). The analysis purposed to assess if the relationship between the human resources practices, which is operationalised as training and development, participation in decision-making, rewards and recruitment and selection (independent variables), and the dependent variables of experimentation and risk-taking, can be explained by the mediating variable of person-job fit. The mediating effect of person-job fit on both experimentation and risk-taking were analysed separately. The analysis indicated that there is a significant indirect effect of training and development (0.29), participation in decision-making (0.26), rewards (0.27) and recruitment and selection (0.09) on experimentation through person-job fit. Additionally, a significant indirect effect of training and development $(0.20)$, participation in decisionmaking (0.18), rewards (0.18) and recruitment and selection (0.06) on risk-taking through person-job fit was determined. The indirect effects analysis was set at 95\% bootstrap confidence intervals based on 5000 bootstrap samples (Hayes et al. 2014). The total effects (Kane \& Ashbaugh, 2017) results indicated the impact of training and development, participation in decision-making, rewards and also recruitment and selection on experimentation and risk taking, without the mediating effect of person-job fit (excluded). The direct effect analysis indicates the impact of training and development, participation in decision-making, rewards and recruitment and selection, as well as person-job fit, as both independent variables. Mediation has occurred, as highlighted by the size of the indirect effect, though relatively low for recruitment and selection $(b=0.09,95 \%$ CI [0.04; $0.15])$ in the experimentation analysis, and also $b=0.06,95 \%$ CI $(0.03 ; 0.10)$ for risk-taking. Importantly, all the confidence intervals do not contain zero, which alludes to the occurrences of mediation for all the variables (Kane \& Ashbaugh, 2017) as reported in Table 6 .

\section{Discussion}

The findings definitively suggest that the human resources practices have a positive relationship as well as an impact on the employee's behavioural outcomes of experimentation and risk-taking. These findings are consistent with the previous research which emphasises the criticality of human resources practices in positively influencing organisational behavioural and performance outcomes. The empirical findings of Niazi (2011) and Falola et al. (2014) corroborate the current study which suggests that training and development is critical for improving business skills, knowledge and competencies, which are critical for performance improvement leading to 
TABLE 6: Mediation analysis.

\begin{tabular}{|c|c|c|c|c|c|}
\hline Variables & Independent $(X)$ & Mediator $(M)$ & Direct effect $(X$ on $Y)$ & Indirect effect $(X$ on $Y)$ & Total effect $(X$ on $Y)$ \\
\hline \multicolumn{6}{|c|}{ Model experimentation } \\
\hline Training & $b=0.51, p=0.000$ & $b=0.58, p=0.000$ & $b=0.71, p=0.000$ & $b=0.29,95 \% \mathrm{Cl}(0.20 ; 0.39)$ & $b=1, t=12.60, p=0.000$ \\
\hline Participation & $b=0.50, p=0.000$ & $b=0.51, p=0.000$ & $b=0.71, p=0.000$ & $b=0.26,95 \% \mathrm{Cl}(0.16 ; 0.35)$ & $b=0.97, t=13.78, p=0.000$ \\
\hline Rewards & $b=0.52, p=0.000$ & $b=0.52, p=0.000$ & $b=0.81, p=0.000$ & $b=0.27,95 \% \mathrm{Cl}(0.17 ; 0.36)$ & $b=1.08, t=14.13, p=0.000$ \\
\hline Recruitment & $b=0.11, p=0.000$ & $b=0.87, p=0.000$ & $b=0.08, p=0.120$ & $b=0.09,95 \% \mathrm{Cl}(0.04 ; 0.15)$ & $b=0.18, t=2.95, p=0.000$ \\
\hline \multicolumn{6}{|c|}{ Model risk taking } \\
\hline Training & $b=0.51, p=0.000$ & $b=0.40, p=0.000$ & $b=0.48, p=0.000$ & $b=0.20,95 \% \mathrm{Cl}(0.12 ; 0.29)$ & $b=0.68, t=8.79, p=0.000$ \\
\hline Participation & $b=0.50, p=0.000$ & $b=0.36, p=0.000$ & $b=0.47, p=0.000$ & $b=0.18,95 \% \mathrm{Cl}(0.09 ; 0.27)$ & $b=0.65, t=9.36, p=0.000$ \\
\hline Rewards & $b=0.52, p=0.000$ & $b=0.36, p=0.000$ & $b=0.54, p=0.000$ & $b=0.18,95 \% \mathrm{Cl}(0.10 ; 0.27)$ & $b=0.73, t=9.70, p=0.000$ \\
\hline Recruitment & $b=0.11, p=0.000$ & $b=0.58, p=0.000$ & $b=0.15, p=0.000$ & $b=0.06,95 \% \mathrm{Cl}(0.03 ; 0.10)$ & $b=0.21 t=3.79, p=0.000$ \\
\hline
\end{tabular}

organisational competitiveness. Similar to the outcomes of Bhatti and Qureshi (2007), Kuyea and Sulaimonb (2011) and Han et al. (2010), participation in decision-making by employees yields positive organisational behavioural outcomes and enhanced performance. The literature analysis of Hsieh and Chen (2011) and Kwon et al. (2013) emphasise the criticality of linking employee behaviour and performance outcomes to rewards which support the overall organisational strategy. Amongst all the human resources dimensions tested, recruitment surprisingly has a low contribution towards improving experimentation and risk-taking work behaviours. The consistently low reports on recruitment and selection are counter-intuitive, especially if recruitment and selection is considered critical in attracting skills into organisations (Steiber \& Alänge, 2013), for performance improvement purposes.

Person-job fit has shown to have both a positive relationship and influence on the proactive experimentation and risktaking work behaviours. The empirical findings of this study on person-job fit are supported by the results of Li and Hung (2010) and June and Mahmood (2011), which suggest that a person's competence, knowledge, skills and experience positively influence job and task performance, which may influence motivation, engagement and commitment behaviours. There is a significant indirect effect of human resources practices - operationalised as training and development, participation in decision making, rewards and recruitment and selection - on experimentation and risktaking work behaviours, through person-job fit. This finding confirms that person-job fit is both a mediator as well as a predictor of organisational behavioural and performance outcomes (Boon et al., 2011; Li \& Hung, 2010).

In general, the key empirical findings of this study support the predictions that human resources practices positively impact on the cultivation and enablement of proactive experimentation and risk-taking work behaviour. Furthermore, person-organisational fit mediates the relationship between the human resource practices and the proactive experimentation and risk-taking work behaviour.

\section{Theoretical contributions}

The research makes very important contributions to the literature of organisational performance and human resources. Firstly, the empirical analysis demonstrates how and which human resources practices affect organisational performance. To our knowledge, there are few studies which have been conducted on the impact of human resources on the proactive employee behaviours, such as experimentation and risk-taking, which still needs further uncovering and exploration. However, the research on human resource contribution towards influencing organisational outcomes such as performance, motivation and commitment has gained solid progression and still holds strong potential for further research (Ahmad \& Schroeder, 2002; Bhatti \& Qureshi, 2007; Han et al., 2010; Niazi, 2011), more specifically on organisational learning-related behaviours such as experimentation and risk-taking which are critical in organisational creativity, innovation and continuous improvement-related work activities. These findings are consistent with organisational learning theory which aims to improve organisational innovation, entrepreneurship, creativity and continuous improvement capacity in order to improve organisational competitiveness. Secondly, the findings iterate that proactive employee behaviours enable the identification of opportunities in the market environment leading to product, process and strategy adaptations which are geared towards value-addition, business improvement and growth. Finally viewing of human resources practices as strategic enablers, which contribute towards organisational effectiveness, performance and competitiveness, reveals the economic and value-adding contribution of the human resources field.

\section{Practical managerial implications}

The overall contribution of the study was to offer management and the human resources function some empirical and theoretical grounding towards the enhancement of organisational performance which impacts on organisational competitiveness and sustainability. The distinction between the operationalised human resources dimensions which impact on experimentation and risk-taking behaviours has been examined and highlighted. In fact, the study has revealed and demonstrated that training and development, participation in decision-making, rewards and person-job fit significantly contribute towards proactive work behaviours. Organisational management can propose concrete human resources strategies for changes necessary towards improving experimentation and risk-taking work behaviours, which underline innovativeness, continuous improvement, 
organisational learning and creativity outcomes. Although recruitment and selection indicated a low relationship and impact on experimentation and risk-taking behaviours, Ahmad and Schroeder (2002), as well as Hsiao et al. (2011), assert that recruitment and selection is a critical human resource function. The recruitment function identifies and attracts key talent to the organisation which fits with organisational and job requirements as far as behaviour, skills, knowledge and competence are concerned; in contrast, the outcome of this analysis suggests a lesser role of recruitment as far as experimentation and risk-taking work behaviour is concerned.

\section{Limitations and recommendations}

Despite the modest contributions of this study, a few limitations exist which point to the direction of future research. Firstly, experimentation and risk-taking are rather complex work behavioural concepts that need to be studied further, and more specifically, what enhances and improves them. The study emphasised on the specific human resources aspects, but it would be interesting to conduct future studies which focus on the impact of organisational strategy, organisational structural configuration as well as leadership. Qualitative studies utilising interviews, asking participants to identify organisational factors which improve proactive experimentation and risk-taking employee behaviour would be beneficial. Additionally, the study adopted its once off survey design format rendering the results exploratory and developmental, which necessitates repeated longitudinal research in this type of study.

\section{Conclusion}

The results of the study demonstrated the criticality of human resource interventions in supporting and enabling organisational performance and behavioural outcomes, and more specifically with proactive behaviours of experimentation and risk-taking, which underpin initiatives such as continuous improvement, innovation and creativity at process, product and service levels. The important outcomes of the research are that rewards, participation in decision-making, training and development, as well as person-job fit are essential for the creation of conditions which cultivate proactive and productive organisational behavioural outcomes.

\section{Acknowledgements Competing interests}

The authors confirm that there is no conflict of interest.

\section{Authors' contributions}

All authors contributed equally to this work. R.B.M. was involved in execution and writing of the study. A.G. is the data owner, and provided leadership oversight and guidance for the study.

\section{Funding information}

This research received no specific grant from any funding agency in the public, commercial or not-for-profit sectors.

\section{Ethical consideration}

Ethical clearance was approved by the ethics committee of the business school. The permission to conduct research was granted by the participating organisation's authority figures (Ref \#:2018_SBL_003_CA).

\section{Data availability statement}

Data sharing is not applicable to this article as no new data were created or analysed in this study.

\section{Disclaimer}

The views and opinions expressed in this article are those of the authors and do not necessarily reflect the official policy or position of any affiliated agency of the authors.

\section{References}

Ahmad, S., \& Schroeder, R.G. (2002). The importance of recruitment and selection process for sustainability of total quality management. International Journal of Quality \& Reliability Management, 19(5), 540-550. https://doi.org/10.1108/ 02656710210427511

Alpkan, L., Bulut, C., Gunday, G., Ulusoy, G., \& Kilic, K. (2010). Organizational support for intrapreneurship and its interaction with human capital to enhance innovative performance. Management Decision, 48(5), 732-755. https://doi.org/10.1108/ 00251741011043902

Anderson, C., \& Galinsky, A.D. (2006). Power, optimism, and risk-taking. European Journal of Social Psychology, 36(4), 511-536. https://doi.org/10.1002/ejsp.324

Arshi, T., \& Burns, P. (2018). Entrepreneurial architecture: A framework to promote innovation in large firms. The Journal of Entrepreneurship, 27(2), 151-179. https://doi.org/10.1177/0971355718781245

Bhatti, K.K., \& Qureshi, T.M. (2007). Impact of employee participation on job satisfaction, employee commitment and employee productivity. International Review of Business Research Papers, 3(2), 54-68.

Boon, C., Den Hartog, D.N., Boselie, P., \& Paauwe, J. (2011). The relationship between perceptions of HR practices and employee outcomes: Examining the role of person-organisation and person-job fit. The International Journal of Human Resource Management, 22(1), 138-162. https://doi.org/10.1080/09585 192.2011.538978

Botma, Y., Greeff, M., Mulaudzi, F.M., \& Wright, S.C.D. (2010). Research in health sciences (1st edn.). Cape Town: Pearson Education.

Cable, D.M., \& De Rue, D.S. (2002). The convergent and discriminant validity of subjective fit perceptions. Journal of Applied Psychology, 87(5), 875-884. https:// doi.org/10.1037//0021-9010.87.5.875

Cannon, M.D., \& Edmondson, A.C.E. (2005). Failing to learn and learning to fail (Intelligently): How great organizations put failure to work to innovate and improve. Long Range Planning, 38(3), 299-319. https://doi.org/10.1016/j.Irp. 2005.04.005

Chiva, R., Alegre, J., \& Lapiedra, R. (2007). Measuring organisational learning capability among the workforce. International Journal of Manpower, 28(3/4), 224-242. https://doi.org/10.1108/01437720710755227

Chiva, R., Alegre, J., \& Lapiedra, R. (2008). Assessing the impact of organizational learning capability on product innovation performance: An empirical test. Technovation, 28(6), 315-326. https://doi.org/10.1016/j.technovation.2007.09.003

Corine Boon ,C. Deanne N. Den Hartog, Paul Boselie \& Jaap Paauwe (2011) The relationship between perceptions of HR practices and employee outcomes: examining the role of person-organisation and person-job fit, The International Journal of Human Resource Management, 22:01,138-162, DOI: 10.1080/09585192.2011.538978

Delaney, J.T., \& Huselid, M.A. (1996). The impact of human resource management practices on the perceptions of organisational performance. Academy of Management Journal, 39(4), 949-969. https://doi.org/10.2307/256718

Dermol, V., \& Čater, T. (2013). The influence of training and training transfer factors on organisational learning and performance. Personnel Review, 42(3), 324-348. https://doi.org/10.1108/00483481311320435 
Edvardsson, I.R. (2008). HRM and knowledge management. Employee Relations, 3(5) 553-561. https://doi.org/10.1108/01425450810888303

Falola, H.O., Osibanjo, A.O., \& Ojo, S.I. (2014). Effectiveness of training and development on employees' performance and organisation competitiveness in the Nigerian Banking Industry. Bulletin of the Transilvania University of Braşov, Series Volume - Economic Sciences, 7(56), 161-170.

Farrell, M.A. (2000). Developing a market-oriented learning organisation. Australian Journal of Management, 25(2), 201-221. https://doi.org/10.1177/031289 620002500205

Field, A. (2018). Discovering statistics using IBM SPSS statistics (5th edn.). London: Sage.

Fong, C., Ooi, K., Tan, B., Lee, V., \& Chong, A. (2011). HRM practices and knowledge sharing: An empirical study. Journal of Manpower, 32(6), 704-723. https://doi. org/10.1108/01437721111158288

Griffin, M.M., \& Steinbrecher, T.D. (2013). Large-scale datasets in special education research. International Review of Research in Developmental Disabilities, 45 155-181. https://doi.org/10.1016/B978-0-12-407760-7.00004-9

Grobler, A. (2016). Person-organisational fit: A revised structural configuration Journal of Applied Business Research, 32(5), 1419-1434. https://doi.org/ 10.19030/jabr.v32i5.9769

Grobler, A., Grobler, S., \& Mathafena, R. (2019). Measurement of the perceptions of human resource practices in a seemingly collectivistic culture. SA Journal of Human Resource Management/SA Tydskrif vir Menslikehulpbronbestuur, 17, Human Resource Management/SA Tydskrif vir Menslikeh
article 1069. https://doi.org/10.4102/sajhrm.v17i0.1069

Guinot, J., Chiva, R., \& Mallen, F. (2016). Linking altruism and organizational learning capability: A study from excellent human resources management organizations in Spain. Journal of Business Ethics, 138, 349-364. https://doi.org/10.1007/s10551Spain. Jour

Han, T.S., Chiang, H.H., \& Chang, A. (2010) Employee participation in decision making, psychological ownership and knowledge sharing: Mediating role of organizational commitment in Taiwanese high-tech organizations. The International Journal of Human Resource Management, 21(12), 2218-2233. https://doi.org/10.1080/095 85192.2010.509625

Hayes, A.F., \& Preacher, K.J. (2014). Statistical mediation analysis with a multicategorical independent variable. British Journal of Mathematical and Statistical Psychology, 67, 451-470. https://doi.org/10.1111/bmsp.12028

Hsiao, W., Chang, T., Huang, M., \& Chen, Y. (2011). Selection criteria of recruitment for information systems employees: Using the analytic hierarchy process (AHP) method. African Journal of Business Management, 5(15), 6201-6209.

Hsieh, Y.H., \& Chen, H.M. (2011). Strategic fit among business competitive strategy, human resource strategy and reward system. Academy of Strategic Managemen Journal, 10(2), 11-32.

Iplik, F.N., Kilic, K.C., \& Yalcin, A. (2011). The simultaneous effects of person organization and person job fit on Turkish hotel managers. International Journal of Contemporary Hospitality Management, 23(5), 644-661. https://doi.org/10. 1108/09596111111143386

Irawanto, D.W. (2015). Employee participation in decision-making: Evidence from a state-owned enterprise in Indonesia. Management, 20(1), 159-172.

Jerez-Gómez, P., Céspedes-Lorente, J., \& Valle-Cabrera, R. (2005). Organizational learning and compensation strategies: Evidence from the Spanish chemical learning and compensation strategies: Evidence from the Spanish chemical industry. Human

June, S., \& Mahmood, R. (2011). The relationship between role ambiguity, competency and person-job fit with the job performance of employees in the service sector SMEs in Malaysia. Business Management Dynamics, 1(2), 79-98.

Kalmuka, G., \& Acar, A.Z. (2015). The mediating role of organizational learning capability on the relationship between innovation and firm's performance: A conceptual framework. In C. Zehir \& E.E. Özdemir (Eds.), Procedia - Social and behavioral sciences, 4th International Conference on leadership, technology, innovation and business management (vol. 210, pp. 164-169). https://doi. innovation and business managem

Kane, G.C., \& Alavi, M. (2007). Information technology and organizational learning: An investigation of exploration and exploitation processes. Organization Science, 18(5), 796-812. https://doi.org/10.1287/orsc.1070.0286

Kane, L., \& Ashbaugh, A.R. (2017). Simple and parallel mediation: A tutorial exploring anxiety sensitivity, sensation seeking, and gender. The Quantitative Methods for Psychology, 13(3), 148-165. https://doi.org/10.20982/tqmp.13.3.p148

Kehoe, R.R., \& Wright, P.M. (2013). The impact of high-performance human resource practices on employees' attitudes and behaviors. Journal of Management, 39(2) 366-391. https://doi.org/10.1177/0149206310365901

Kreiser, P.M., \& Davis, J. (2010). Entrepreneurial orientation and firm performance: The unique impact of innovativeness, proactiveness, and risk-taking. Journal of Small Business \& Entrepreneurship, 23(1), 39-51. https://doi.org/10.1080/08276 331.2010.10593472

Kristof-Brown, A.L. (2000). Perceived applicant fit: Distinguishing between recruiters' perceptions of person-job and person-organization fit. Personnel Psychology, 53(3), 643-671. https://doi.org/10.1111/j.1744-6570.2000.tb00217.x

Kuratko, D.F., Hornsby, J.S., \& Covin, J.G. (2014). Diagnosing a firm's internal environment for corporate entrepreneurship. Business Horizons, 57(1), 37-47. environment for corporate entrepreneurship.
https://doi.org/10.1016/j.bushor.2013.08.009
Kuyea, O.L., \& Sulaimonb, A.A. (2011). Employee involvement in decision making and firms performance in the manufacturing sector in Nigeria. Serbian Journal of Management, 6(1), 1-15. https://doi.org/10.5937/sjm1101001K

Kwon, J., Hewitt, A., \& Hein, P. (2013). Employee benefits in a total rewards framework. Benefits Quarterly, 29(1), 32-38.

Leat, M., \& El-Kot, G. (2007). HRM practices in Egypt: The influence of national context? The International Journal of Human Resource Management, 18(1), 147-158. https://doi.org/10.1080/09585190601068557

Leedy, P.D., \& Ormrod, J.E. (2016). Practical research: Planning and design (11th edn.). Boston, MA: Pearson Education.

Li, C., \& Hung, C. (2010). An examination of the mediating role of person job fit in relations between information literacy and work outcomes. Journal of Workplace Learning, 22(5), 306-318. https://doi.org/10.1108/13665621011053217

Liu, S.S., Luo, X., \& Shi, Y. (2002). Integrating customer orientation, corporate entrepreneurship, and learning orientation in organizations-in-transition: An empirical study. International Journal of Research in Marketing, 19(4), 367-382. https://doi.org/10.1016/S0167-8116(02)00098-8

Lu, C., Wang, H., Lu, J., Du, D., \& Bakker, A.B. (2014). Does work engagement increase person-job fit? The role of job crafting and job insecurity. Journal of Vocational Behavior, 84(2), 142-152. https://doi.org/10.1016/j.jvb.2013.12.004

Martins, E.C., \& Terblanche, F. (2003). Building organisational culture that stimulates creativity and innovation. European Journal of Innovation Management, 6(1), 64-74. https://doi.org/10.1108/14601060310456337

Mathews, P. (2006). The role of mentoring in promoting organizational competitiveness. Competitiveness: Review. International Business Journal, 16(2) 158-169. https://doi.org/10.1108/10595420610760743

Miron, W., \& Hudson, D. (2014). Enabling employee entrepreneurship in large technology firms. Technology Innovation Management Review, 4(2), 23-32. https://doi.org/10.22215/timreview/766

Nafukho, F.M., Graham, C.M., \& Muyia, M.H. (2009). Determining the relationship among organizational learning dimensions of a small size business enterprise. Journal of European Industrial Training, 33(1), 32-51. https://doi.org/10.1108/ 03090590910924360

Niazi, A.S. (2011). Training and development strategy and its role in organizational performance. Journal of Public Administration and Governance, 1(2), 42-57. https://doi.org/10.5296/jpag.v1i2.862

Onağ, A.O., Tepeci, M., \& Başalp, A.A. (2014). Organizational learning capability and its impact on firm innovativeness. In M. Özşahin (Ed.), Procedia - Social and behavioral sciences, 10th International strategic management conference (vol. 150, pp. 708-717). https://doi.org/10.1016/j.sbspro.2014.09.029

Pallant, J. (2016). SPSS survival manual: A step by step guide to data analysis using SPSS program (6th edn.). London: McGraw-Hill Education.

Riabacke, A. (2006). Managerial decision making under risk and uncertainty. IAENG International Journal of Computer Science, 32(4), 1-7.

Spicer, D.P., \& Sadler-Smith, E. (2006). Organizational learning in smaller manufacturing firms. International Small Business Journal, 24(2), 133-158. https://doi.org/ 10.1177/0266242606061836

Steiber, A., \& Alänge, S. (2013). A corporate system for continuous innovation: The case of Google Inc. European Journal of Innovation Management, 16(2), 243-264. https://doi.org/10.1108/14601061311324566

Suartha, N., \& Suprapti, N.W.S. (2016). Entrepreneurship for students: The relationship between individual entrepreneurial orientation and entrepreneurial intention. European Journal of Business and Management, 8(11), 45-52.

Sung, S.Y., \& Choi, J.N. (2014). Do organizations spend wisely on employees? Effects of training and development investments on learning and innovation in organizations. Journal of Organizational Behavior, 35(3), 393-412. https://doi. org/10.1002/job.1897

Sutanto, E.M. (2017). The influence of organizational learning capability and organizational creativity on organizational innovation of Universities in East Java, Indonesia. Asia Pacific Management Review, 22(3), 128-135. https://doi. org/10.1016/j.apmrv.2016.11.002

Terziovski, M. (2001). The effects of continuous improvement and innovation management practice on small to medium enterprise (SME) performance. Parkville: Faculty of Economics and Commerce, The University of Melbourne. pp. 1-22.

Tohidi, H., \& Jabbari, M.M. (2012). Measuring organizational learning capability. Procedia-Social and Behavioral Sciences, 31, 428-432. https://doi.org/10.1016/j. sbspro.2011.12.079

Tsai, H., \& Luan, C. (2016). What makes firms embrace risks? A risk-taking capability perspective. Business Research Quarterly, 19(3), 219-231. https://doi.org/ 10.1016/j.brq.2016.01.002

Urban, B. (2015). Corporate entrepreneurship. In R. Venter \& B. Urban (Eds.) Entrepreneurship theory in practice (3rd edn., pp. 512-547). Cape Town: Oxford Southern Africa.

Wiklund, J., \& Shepherd, D.A. (2011). Where to from here? EO-as-experimentation, failure, and distribution of outcomes. Entrepreneurship Theory and Practice, 35(5), 925-946. https://doi.org/10.1111/j.1540-6520.2011.00454.x 